\title{
Under the "Micro-Age" Learning Behavior Research of CSCL--Based
}

\author{
HuanLe $\mathrm{Zhu}^{1, \mathrm{a}}$, Jinfeng $\mathrm{Li}^{2, \mathrm{~b}}$ and Wenjie Zhang ${ }^{3, \mathrm{c}}$ \\ ${ }^{1}$ Nan Chang Institute of Science \&Technology, Nanchang, China \\ ${ }^{2}$ Nanchang Institute of Sciense \& Technology, Nanchang, China \\ ${ }^{3}$ Nanchang Institute of Sciense \& Technology, Nanchang, China \\ a 516582291@qq.com, b524892454@qq.com, ${ }^{\text {c5} 568740355 @ q q . c o m ~}$
}

Keywords: Micro-Age, CSCL, Learning behavior

\begin{abstract}
The advent of micro-age gradually influence and change the learners' learning styles. In order to explore questions aiding to students in the process of CSCL-based classroom instruction in the western college, firstly, this paper carries out the teaching quasi-experimental, which is based on problem-solving network-based collaborative learning activities by surveying research and quasiexperimental research method. Secondly, this paper sums up some reasons which impact the effect of group learning by intervening, observating and researching the learning process of six cooperative learning groups. Finally, author proposes some strategies related problem-solving, and expect they will provide reference and help to the teaching in the classroom of utilizing the auxiliary CSCL.
\end{abstract}

\section{Introduction}

The so-called computer-supported collaborative learning(CSCL: Computer Supported Cooperative Learning) is a form of learning that small group learners cooperate for achieving a common goal with the construction of knowledge in computer supporting environment(Ronghuai Huang 1999). In recent years, CSCL learning has been widely used. Overall, CSCL in the classroom teaching can be classified two forms: independent and assisted in classroom teaching. However, regardless of the effect of its application form that should be closely related to the learner's learning behaviors and other factors.

The researches of CSCL in China began roughly the late 1990s, researchers in China have done a lot of work in this field of study, such as Beijing Normal University Professor Ronghuai Huang wrote the book "computer-supported collaborative learning - Theory and Methods", Professor Huang and his students have done more systematic study of related content: theoretical method of collaborative learning, collaborative learning systems model. In addition, "based collaborative learning instructional design" and other papers described this area. By a number of books and literature research analysis author found that domestic research in this field focused on CSCL theory and methods, CSCL interaction study, CSCL technology research and application results in terms of learning activities in the learner's learning behavior was more less.

However, collaborative learning study abroad earlier than domestic, which began about 1980s. By analysis information the author found researchers mainly come from outside the United States, Canada, Britain and other countries. Some related papers published in leading academic journals: Educational Technology, Educational Technology Research and Development and so on. They research deeply in this field such as: David H. Jonassen and LueiaRohrer-Murphy from the need to build a modern learning environment, the introduction of behavior theory, analysis behaviors of modern learning environment factors. Morever, foreign researchers are also concerned about the control and guidance of the learning behavior.

\section{Research Methods}

This study used a survey method and quasi-experimental research method. Survey method is a purposeful, planned, systematic way to understand some of the actual situation and to find the 
problems and the laws (Huaiyin Hou 2009). The specific research method has many ways, such as literature, questionnaire survey, interview and so on. In this paper, the author early access to a lot of research literatures about CSCL and ask a hypothetical status: What are the factors about impacting aid students in western universities network of collaborative classroom learning? Then in the early and mid-term learning activities and through the network platform for the survey I carried out questionnaire survey "learning style measure", "problem-solving ability to measure" and "online learning activities survey" for scientific grouping learners, adjusting and improving the design of learning activities. After the end of a learning activity, according to the performance of learners in the learning process (mainly based on learning outcomes and post submitted by the quantity and quality) selecting representative individual learners were interviewed to understand their problems in the learning activities, and in the follow-up activities some proper interventions will be adopted to ensure the efficiency of learning outcomes. Quasi-experimental research method: it is a method that using the original group, author do experimental research in a more natural case $(\mathrm{Mu} S u$ 2001).While this experiment were divided into three types of collaborative learning groups according to homogeneous and heterogeneous grouping principles, author design some different interventions in learning activities and take different strategies to ensure the authenticity and validity of experimental results.

\section{The Design of Experiments}

"Principle of modern educational technology" is the basic course of the Educational Technology , using the online collaborative discuss learning plus the traditional face to face teaching mode. Every Wednesday afternoon,firstly teacher focuses on the classroom teaching, after-school students primarily through Abou Teaching Platform for web-based collaborative problem-solving learning. To make learners learn better and more effective collaboration in the learning activities,author carried out prior problem-solving ability and learning style network survey in the whole class then according to the principle of the homogeneous and heterogeneous grouped students into homogeneous group, heterogeneous group and mixed group(six groups and each group 4-5 persons). In the learning process learners mainly through "Notice Information" to obtain feedback and suggestions. The" syllabus "clear the main content of learning activities and mission requirements and the" communication tools "in the discussion board is the core of support for the exchange of learners. In the discussion board, learners can initiate a topic of discussion and can also be initiated to respond to others topics, the entire learning process was took a completely voluntary basis.

The experiment focused on the team-based and problem-solving of collaborative learning activities experience. It can be divided into the following four steps:

The first step: knowing the network teaching platform. To enable learners to obtain better network collaborative learning, before the start of the event, firstly supplementary managers introduce network teaching platform for learners on the function. Focusing the discussion board as the main venue for learning methods and principles, so that students have the appropriate network teaching platform skills and smoothly access to the data after activities.

The second step: forming collaborative learning groups. In this study, firstly author investigates learners learning styles and problem-solving capacity on network questionnaire, then in accordance with the principles of homogeneous and heterogeneous she divides 26 students into the scale of 4-5 person, different qualitative and mixed groups are three types of study groups. So according different groups she can takes different implementations, and monitors and intervents their activities, then validate the learner's learning style and effects.

The third step: carrying out collaborative learning network. At first,Collaborative learning activities creat learning environment and guide students to actively participate in collaborative problem-based learning, collaborative learning tools and resources acting as a social medium to communicate effectively to support learning and collaboration(Lorraine Sherry,Havelock Bruce 2005).Thus,firstly puting the "principle of modern educational technology" course outlines and the general requirements and needs of learners together, then design the appropriate context of problem-based learning activities. Learners according to the "Syllabus" displaying in learning 
materials, learn tasks and topics, aids and resources related to knowledge of consultation, discussion and learning. Aiding managers are involved in each learning groups, counseling and assistance to learners to encourage and urge them to actively participate in activities

The step four: feedback and summary. Asynchronous and metachronous collaborative learning network make the feedback process in the learning activities become more important. The lack of Feedback results in a complete activity can't play the system to adjust, adapt and change potential(G. Simmons 2009). The feedback of this experiment can't be throughout the process, supplementary teaching should timely land the platform and concern about learning in all study groups (mainly posts and replies) and give timely feedback. Each collaborative group will eventually have to submit the results of consultation and discussion of the learning activities, the forms of results can be diversity as much as possible, such as PPT, Excel tables, Word documents, mindmaps and so on. Finally, in "Information Bulletin" managers will give the final evaluation of learning activities. Simultaneously, after each learning activity, we will organize a face to face exchange of learning to share each group's learning experience and results, deepening the learning experience and understanding of this learning form. The experimental flow of this activities is shown in Fig.1.

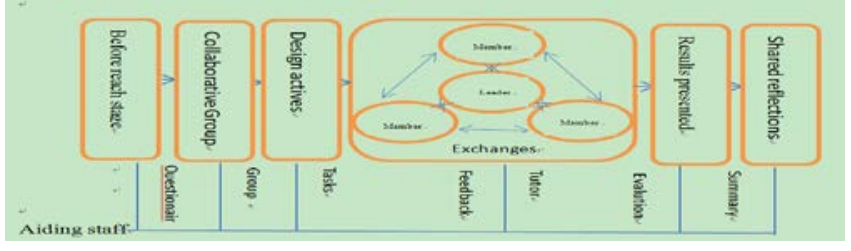

Fig.1. Flow of Learning Activities

\section{Experimental Results Analysis}

Problem Found. Look beyond the surface. From the number of learners to access the platform, the quality of returning posts,the analysis of the results I map out some problems about the learners in the classroom network collaborative learning activities.

The analysis of visits. In the mid- activities ,I summary a number of the learner visits statistics (chart below) and found that more than half of the learner does not meet the average number of visits, and even individual learners do not participate in learning activities, completely as a "bystander." This phenomenon indicates that the individual learning in collaborative learning activities of individuals are not enthusiastic, and less motivated to participate.

The analysis of quantity and quality posts. the main goal of CSCL-based learning activities is to help learners construct knowledge, and the situation of constructing knowledge can be showed through the quantity and quality of the post. The more shows the number of activities for learners of positive thinking and response, post replies content and quality is reflected in the degree of matching topic or task, the higher the quality of learner's knowledge construction better. On the first learning activity, the number of posts is 175, but further analysis I found that the number of the posts of mixed collaborative group are more than homogeneous collaborative group, heterogeneous group in between. This shows that learning styles affect the learning outcomes for learners. Simultaneously, the author conducted a content analysis of some posts, hybrid collaborative group posts and tasks are mostly to coincide with the topic of collaboration and shallow depth of content. It also shows that the above conclusion.

The analysis of results. Learning outcomes are important indicators of evaluating whether the learner meet learning objectives or not. From the analysis of the first results submitted from each study group learning activities, I found that the results have been submitted to the formal requirements of the majority group using Excel spreadsheet, Word document or mindmaps and many other forms, but the team nonrequired is almost all used Word form. This phenomenon indicates that the learners are more dependent on supplementary staff, lacking independent thinking and innovation ability. The author compares the learning process and learning outcomes content and then found that some groups in the consultations and discussions are very successful in the learning process. However, learning outcomes to submit the content and form are 
obviously alone and does not reflect the group's real learning. This shows that the abilities of the learners on the network and adapts to the collaborative learning process, and their ability of summary of the data of learning outcomes are poor.

Problem-solving. Through the above analysis found that concerns about the form of learnerbased learning activities in CSCL do exist. The author chose five representative individual learners interviewed, combined with the interview results, and made the following problems-solving strategies:

In the process of assisted in teaching of collaborative learning network, giving learners some appropriate "authority of the pressures" will help to improve the learner's active participation. Although the objects of this experiment were graduate students they were found still lacking selfdriving force. In some cases, this self-driving force is necessary for teachers to stimulate and promote and to avoid the"on the sidelines " of collaborative learning activities appearing.

According to the analysis, both the design of CSCL in learning activities and the quality of online teaching platform affect the power of the learners to participate in the activities. Therefore, designers and aiding managers should pay attention to the amount of the task, the designing forms of problems, tools and micro learning resources and network teaching platform stability and so on.

It was found that the learning styles of learners affect the learner's learning outcomes. From the analysis of the results can be seen with the same learning styles of learners having a strong dependence. Acessing to individual learners found that some of the group in some collaborative task is almost completed by one person. Obviously, the tasks designing should be structured and differentiated. Guaranteed the achievement of learning objectives in the case, the form of tasks can be varied, and within the group the tasks can establish its own role to ensure that the true occurrence of collaborative learning activities.

\section{Conclusion}

Computing, digital and network technology play important roles in CSCL research, along with new technology applications in education, they are bound to bring new inspirations to education reform(Shaoming Chai, Jianhua Zhao 2011). The learning forms of CSCL-based and aiding classroom teaching have good effects on deepening classroom teaching. Due to some reasons such as regional economy, a number of the western colleges learners show some inadaptations in the CSCL-assisted learning environment, but designers can design learning activities through the use of micro video, micro test, the application of micro feedback, which affect the effect of learning. Although the article only carried out small-scale experimental design and learner follow-up survey, it also illustrates some problems.

\section{References}

[1] Ronghuai Huang. Theory and Method of CSCL,J. e-Education Research, 1999, (6).

[2] Huaiyin Hou .Educational Research Methods,M. Beijing:Higher Education Press, 2009,(146).

[3] Su Mu. Quasi-experimental study and its design method,J. CET China Educational Technology, 2001, (12).

[4] Lorraine Sherry, Havelock Bruce (2005). The Personal and Professional Learning portfolio: An Onlion Environment for Mentoring, Collaboration, and Publication [A].Roberts Tim S.(Eds).Computer-Supported Collaborative Learning in Higher Education [C].Hershey PA:Idea Group Publishing,2005.p.210-217.

[5] G. Simmons . Internet era of knowledge and learning - to connect,M. Shanghai:East China Normal University Press, 2009,(102).

[6] Shaoming Chai, Jianhua Zha.CSCL of the View of Education Policy and Practice---CSCL2011International Conference Overview,J. Journal of Distance Education,2011,NO5,(20). 